\title{
OS DETERMINANTES DA OFENSIVA NEOLIBERAL SOBRE O CURRÍCULO DE GEOGRAFIA PARA A EDUCAÇÃO DE JOVENS E ADULTOS
}

\author{
The determinants of the neoliberal offensive on the geography curriculum for youth and \\ adult education \\ Rodrigo Coutinho Andrade * \\ *Professor do Departamento de Geografia IM/UFRRJ - rodrigoandrade@ufrrj.br.
}

\begin{abstract}
Resumo:
O processo de reestruturação da Educação de Jovens e Adultos (EJA) no Brasil, em curso após a materialização da ofensiva neoliberal na década de 1990, tem consolidado os determinantes hegemônicos no âmbito das políticas educacionais para essa modalidade de ensino, abarcando tanto a gestão sob as premissas do gerencialismo, quanto os pressupostos político-pedagógicos e curriculares para a formação do "homem de novo tipo". Isto ocorre por meio da consolidação dos valores societários hegemônicos no campo do currículo, impactando o processo de ensino-aprendizagem que se volta progressivamente para a adequação psicofísica da classe trabalhadora às novas morfologias do trabalho, indissociável da juvenilização induzida, da descentralização executiva, da precarização do financiamento e dos programas federais que integram a EJA ao ensino técnico-profissionalizante. Destarte, por meio da análise bibliográfico-documental das áreas de geografia e educação, o presente artigo objetiva expor os impactos do processo de recomposição burguesa nas prescrições curriculares, indicando em seu âmago o recrudescimento da teoria do capital humano, assim como a reconfiguração dos mecanismos de mediação do conflito de classes por meio da sobrevalorização categórica de princípios ancorados na sociabilidade burguesa, e como estes se assentam na relação ensino-aprendizagem em geografia nos programas federais de EJA, tomando o Projovem como exemplo. Como resultado da análise do currículo do programa discriminado, tendo por base as premissas sócio-histórica e os determinantes do bloco no poder, verificamos a materialização de elementos para a ratificação dos valores societários para a formação do "homem de novo tipo", sendo a Geografia, no campo das Ciências Humanas, instrumentalizada para tal finalidade.
\end{abstract}

Palavras-chave: Educação de Jovens e Adultos; Currículo; Ensino de Geografia.

\begin{abstract}
:
The process of restructuring of Youth and Adult Education (EJA) in Brazil, in progress after the neoliberal offensive materialized in the 1990s, has consolidated the hegemonic determinants within the scope of educational policies for this type of education, encompassing both the management under the premisses of managerialism, as well as the political-pedagogical and curricular presuppositions for the formation of the "man of new type". This occurs through the consolidation of hegemonic societal values in the curriculum field, impacting the teaching-learning process that gradually turns to the psychophysical adequacy of the working class to the new morphologies of work, inseparable from induced juvenilization, executive decentralization, precarization financing and federal programs that integrate the EJA to technical-vocational education. Thus, through the bibliographical-documentary analysis of the areas of geography and education, this article aims to expose the impacts of the process of bourgeois recomposition on the curricular prescriptions, indicating in its core the intensification of the human capital theory, as well as the reconfiguration of the mechanisms of mediation of class conflict through categorical overvaluation of principles anchored in bourgeois sociability, and how these are based on the teaching-learning relationship in geography in federal EJA programs, taking Projovem as an example. As a result of the analysis of the curriculum of the discriminated program, based on the socio-historical premises and the determinants of the block in power, we verified the materialization of elements for the ratification of the corporate values for the
\end{abstract}


formation of the "new type man", being the Geography, in the field of Human Sciences, instrumented for this purpose.

Key-words: Adult and youth education; Curricular policies; Teaching geography.

\section{Introdução}

A Educação de Jovens e Adultos (EJA) no país atravessa por um processo de reestruturação ao longo das últimas duas décadas, que abarca tanto a gestão das políticas educacionais dessa modalidade de ensino, quanto a reorientação pedagógico-curricular. Isto devido à descentralizaçãomunicipalização da oferta, indissociável da escolarização integrada à formação profissional como foco na população jovem, aos mecanismos de financiamento, e a recomposição das prescrições curriculares com foco no mundo do trabalho em tempos de desemprego estrutural e na consolidação da cidadania de novo tipo, por meio da reconfiguração dos mecanismos de mediação do conflito de classes (SOUZA, 2015; NEVES, 2005). No entanto podemos ressaltar, tomando os dados Censo Escolar do Instituto Nacional de Estudos e Pesquisas Educacionais Anísio Teixeira (INEP) para a análise da EJA no país, que nos dias atuais ocorre, como reflexo dos pressupostos do gerencialismo e da retomada do caráter neoliberal ortodoxo para a gestão das políticas educacionais, a redução da oferta principalmente no Ensino Fundamental de EJA.

Figura 1 - Evolução do número de matrículas na EJA no Brasil - 2008/2015.

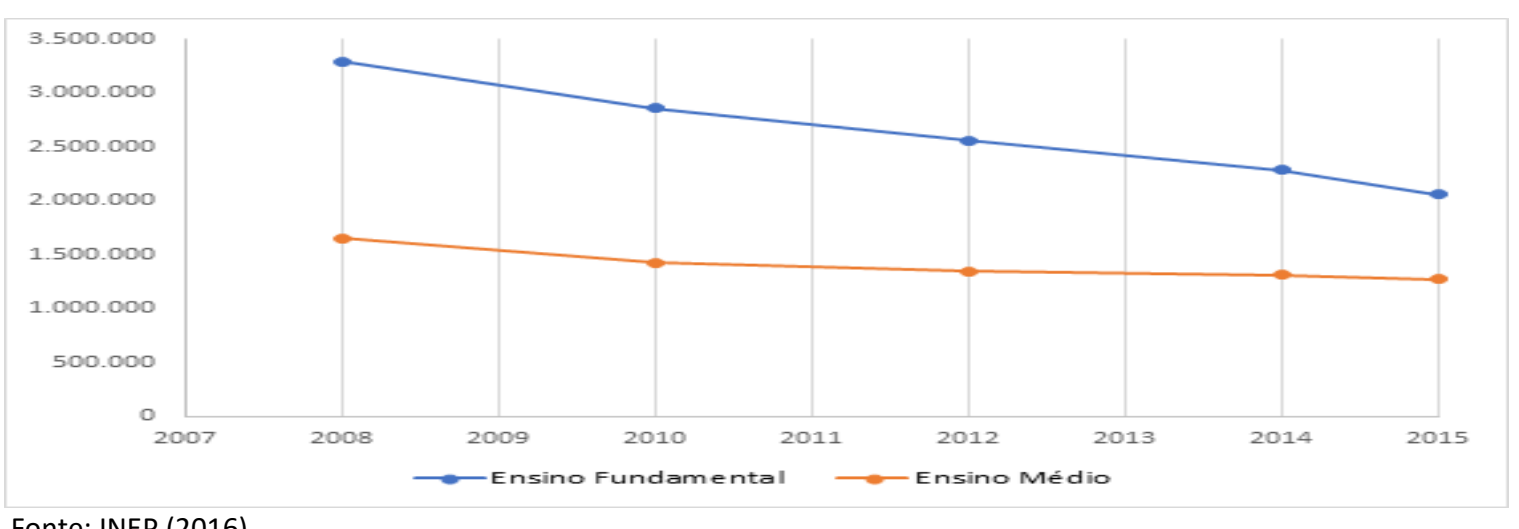

Fonte: INEP (2016).

Nos dias atuais, as medidas para a EJA demarcam um novo ciclo através da retomada das medidas de certificação em larga escala tanto por meio do Exame Nacional para Certificação de Competência de Jovens e Adultos (ENCCEJA), assim como a escolarização pela via da Educação a Distância (EaD) ${ }^{1}$, reconfigurando sob novas faces o caráter supletivo dessa modalidade de ensino, retraído de modo contundente na década passada. Sobre a última característica, resultante do Decreto № 9.057, de 26 de maio de 2017, que regulamenta o Artigo № 80 da Lei de Diretrizes e Bases da Educação Nacional (LDB - Lei № 9.394, de 20 de dezembro de 1996) que trata da criação e ampliação do ensino não presencial, entendido aqui no caso da EJA como intensificação das medidas de certificação em larga escala, reificando o caráter compensatório, precário e aligeirado dessa modalidade de ensino, pontuamos que o mesmo ocorreu de modo autocrático, vide a ausência total de diálogo com as organizações da sociedade civil, nega a identidade da EJA e suas vicissitudes para a formação da classe trabalhadora, e abre um flanco explícito para a privatização dessa modalidade de ensino, que tem como principal meio a oferta pública, vide a presença de $96 \%$ dos matriculados na EJA neste setor (INEP, 2016)2

${ }^{1}$ https://pronatec.pro.br/supletivo-a-distancia-2018/

${ }^{2}$ Esta característica, proeminente nos dias atuais em todos os níveis e modalidade de ensino da educação brasileira, é evidente no caso de EJA, vide a

declaração da presidente da Câmara Superior da Federação Nacional das Escolas Particulares, Amábile Pacios: "se não houver investimento do governo na 
Portanto, o que estamos evidenciando é a recuperação da agenda programática da EJA cristalizada na década de 1990, quando os determinantes hegemônicos impetravam, por meio do financiamento no contexto de ajuste fiscal, o receituário no bojo do ethos competitivo e do setorialismo da oferta, vide a estruturação do Fundo de Manutenção e Desenvolvimento do Ensino Fundamental e de Valorização do Magistério (FUNDEF). Em outras palavras, estamos assistindo o retorno rotundo da ação dos intelectuais orgânicos do capital e suas premissas sobre a EJA, exemplificado por Cláudio Moura e Castro: "o adulto analfabeto já encontrou seu lugar na sociedade. Pode não ser um bom lugar, mas é o seu lugar. (...) Alfabetizar o adulto não vai mudar muito sua posição dentro da sociedade e pode até perturbar. Vamos concentrar os nossos recursos em alfabetizar a população jovem" (HADDAD, 1994, p. 7).

Como exposto, o foco seria a população jovem ainda na década de 1990. Sob a ótica dos intelectuais orgânicos do capital isto seria uma forma de compensar os estudos e a escolarização, mediante a dialética entre a evasão da escola regular e a demanda de escolarização sob a premissa da empregabilidade, afetando diretamente os alunos mais pobres, que até hoje buscam a certificação sob a ideologia da escolaridade básica como mecanismo apologético de ascensão social. Porém, ao longo dos anos o processo de juvenilização, que remarca a identidade da EJA até os dias atuais vide a concentração das matrículas neste segmento sociológico-demográfico, não se restringiu somente a este fator, sendo por nós considerada induzida, atendendo as premissas hegemônicas para essa modalidade de ensino.

Sobre esta hipótese, corroboramos de modo incisivo com o estudo de Souza (2011), onde o autor se refere ao processo de juvenilização dessa modalidade de ensino como medida estratégica diante da acentuação dos problemas enfrentados por esse segmento etário ao longo dos últimos anos, e principalmente a sua potencialidade para ocasionar distúrbios à ordem societária hegemônica. Segundo Souza (2011) e Spósito e Carrano (2003), a redução do analfabetismo da população jovem, assim como seu ingresso massivo na EJA, seria uma das bases para as políticas sociais no início do século XXI, com tendência estratégica à inserção dos jovens excluídos da atividade laboral. Isto se justifica na pesquisa realizada por Souza (2011, p. 17), baseada em dados do Instituto de Pesquisa Econômica Aplicada (IPEA), em que a juvenilização da EJA resulta da concentração de grande parte dos principais problemas sociais dentre a população jovem, envolvendo o maior risco de mortalidade, o alcoolismo e a AIDS. Além disso, constata-se na área educacional que nesta etapa da vida estão os mais significativos indicadores de evasão e repetência. Por essa razão, e sob a ótica do capital, combinam-se nas políticas de EJA a focalização etária intrínseca à formação de novos valores geracionais, como empregabilidade, protagonismo social e a cidadania no bojo da sociabilidade burguesa.

Neste contexto, as políticas públicas de qualificação profissional para a população jovem se inserem no conjunto de políticas de conformação das camadas subalternas com a finalidade de mediar os conflitos de classe e manter a hegemonia do projeto neoliberal. Mais precisamente, tais políticas carregam em si uma pedagogia que inculca nos sujeitos por ela atendidas uma espécie de conformação ética e moral que os tornam sujeitos ativos na construção do consenso em torno do projeto dominante de sociedade (SOUZA, 2011, p. 20).

educação, não haverá sucesso na mudança. Isto poderia ser resolvido com parcerias entre o setor privado e público" (CORREIO BRASILIENSE, 2017, s.p). 
Figura 2 - Número de Matrículas na EJA por Faixa Etária - 2016

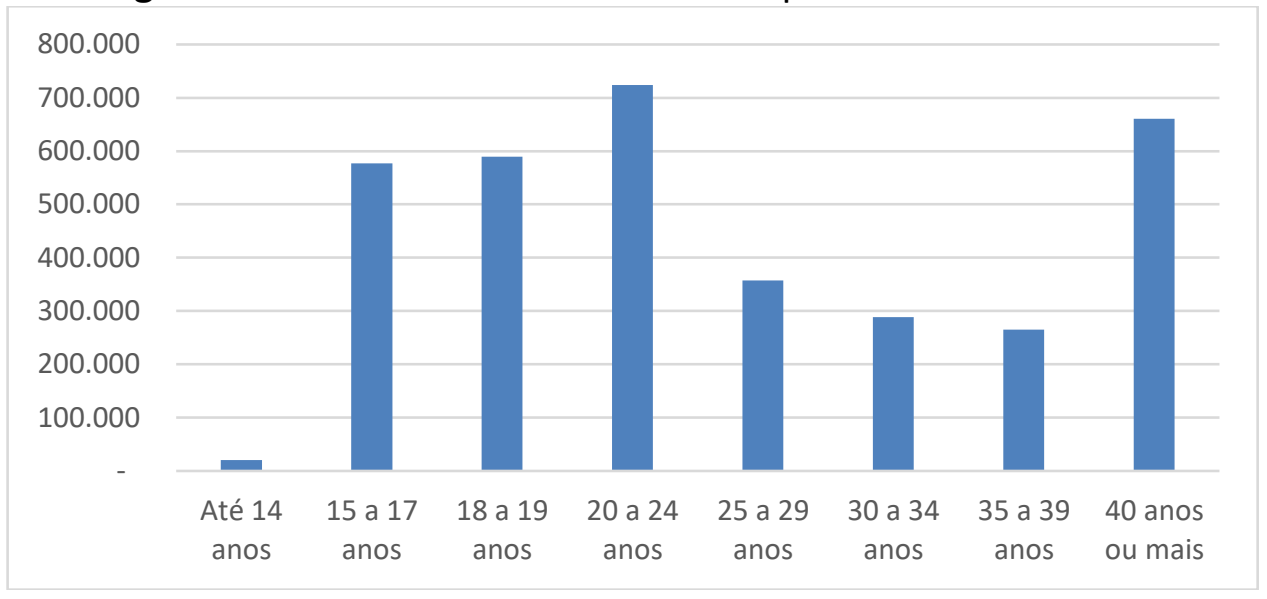

Fonte: INEP (2016

Acerca desta finalidade formativa, explícita no corpo das prescrições curriculares intrínsecos aos determinantes que imputaram as políticas educacionais no contexto de ofensiva neoliberal, que reside o objeto da pesquisa. Sobre isto, identificamos por meio da análise do currículo do programa Projovem Urbano, assim como do manual do estudante, características pedagógico-curriculares para o ensino de Geografia, então diluída no campo das Ciências Humanas, reflexos da reconfiguração ético-política para a formação do homem de novo tipo, "adequado ao novo tipo de trabalho e de processo produtivo [...] a fase da adaptação psicofísica à nova estrutura industrial" (GRAMSCI, 2015, p. 248), vide a sobrevalorização de imperativos morais intrínsecos à sociabilidade burguesa no bojo do recrudescimento da Teoria do Capital Humano3.

Neste sentido, partimos da premissa de que tais transformações são oriundas dos impactos da recomposição burguesa no contexto de crise orgânica do capital ${ }^{4}$ (MÉSZÁROS, 2011), que redimensionaram a totalidade programática da educação brasileira e, portanto, da EJA. A partir desse contexto, tomamos como objeto de análise a cristalização do currículo de Geografia para a EJA, no bojo da oferta dessa modalidade de ensino no programa federal discriminado, diante das intencionalidades sociais, culturais, políticas e econômicas do bloco no poder ${ }^{5}$. Portanto, trata-se de uma pesquisa básica, de análise qualitativa, de caráter explicativo, que se insere na categoria de revisão bibliográfico-documental, desenvolvida a partir do exame das pesquisas sobre o objeto nas áreas de educação e geografia, dos documentos oficiais, e do manual do aluno e currículo do programa discriminado.

\section{Os impactos da ofensiva neoliberal sobre a EJA no Brasil}

A década de 1960 demarca historicamente o esgotamento do regime fordista-taylorista de produção, indissociável da organicidade do capitalismo e o ordenamento do capital ante à reprodução social da vida material. Ou seja, para além das crises cíclicas pretéritas, a presente pode ser entendida como o esgarçamento da reprodução do sistema de valores burgueses em sua

\footnotetext{
3 Segundo Frigotto (2010) e Santos (2006), a Teoria do Capital Humano estaria estruturada no acréscimo marginal de instrução e educação que corresponderia à ampliação da capacidade produtiva. Desse modo, ideologicamente essa tese se sustenta pela necessária educação e qualificação dos trabalhadores, que além de potencializar e gerar mais valor às mercadorias, levaria a superação da desigualdade social, da pobreza e consecutivamente a mobilidade social, ratificando a visão burguesa de homem, sociedade e relações de produção.

${ }^{4}$ Ao longo do texto utilizaremos essa categoria desenvolvida por Gramsci (2000, pp. 36-55) para a análise do esgotamento processual do sistema do capital, considerando intrinsecamente suas elucidações analíticas e metodológicas para a identificação de sua crise, abarcando, sobretudo, a relação dialética entre a superestrutura e a estrutura. No entanto, a forma histórica em que a organicidade do capital se restaura nos dias atuais, se consolida sobre novos imperativos que demarcam seu esgotamento, como visto na análise de Mészáros $(2011 ; 2011 \mathrm{a})$, que tem como princípio básico o colapso do sistema sociometabólico do capital.

${ }^{5}$ Segundo Poulantzas (1978), o conceito refere-se à fração, ou frações, da classe dominante que se aglutina(m) conjunturalmente ao conjunto de estruturas e suas mediações, atuando como uma força social no bojo da própria formação social, que hegemonicamente reproduz a lógica intrínseca das relações de produção na totalidade social.
} 
totalidade sistêmica. Isto é concebido por Mészáros (2011) como a crise estrutural do capital, por tratar-se de uma situação endêmica, radicada na incompatibilidade entre a produção para as necessidades sociais e a reprodução destrutiva e incontrolável do capital, que deriva no rearranjo dos mecanismos de controle sociometabólico' ${ }^{6}$.

A partir de então, a estratégia da burguesia em escala mundial se consolida na produção de mecanismos circunstanciais para a manutenção do regime de acumulação, trazendo à tona novas estratégias para a reprodução do capitalismo, como a aceitação de sua "hibridização"7. Perante esse cenário, a recomposição burguesa passa a buscar, por meio da reestruturação produtiva e da reforma do Estado, a reorientação hegemônica do bloco histórico ${ }^{8}$.

Em relação à estrutura, podemos concebe-la analiticamente pelo desenvolvimento das forças produtivas e das relações sociais de produção em novo patamar técnico, ético, moral, político e tecnológico. Sobre o presente paradigma de caráter toyotista afirmamos, com base nos estudos da Sociologia do Trabalho, que ocorre a intensificação dialética da (ir)racional força destrutiva da sociabilidade moderna, devido à combinação do processo de desindustrialização, desemprego estrutural, intensificação da precariedade do trabalho, desregulamentação de direitos trabalhistas e flexibilização das relações de trabalho, em conjunto ao incremento científico e tecnológico ao longo das últimas décadas ${ }^{9}$.

Entretanto, o grande salto deste estágio produtivo estaria na capacidade da transformação das relações sociais de produção sob a égide da flexibilização, que alcança principalmente o chão-defábrica por meio do "envolvimento cooptado" (ANTUNES, 2011). Propagada sob o discurso da multiplicidade funcional do trabalho e da empregabilidade, a transformação produtiva, no bojo da racionalização da gestão do labor, impõe ao trabalhador novos imperativos, objetivando sua maleabilidade ao processo produtivo.

Isso só foi possível devido à sua capacidade de capturar a subjetividade operária, inaugurando um novo patamar da subsunção do trabalho ao capital, e devido à reconfiguração das condições superestruturais do cotidiano social, caracterizada pelas alterações significativas dos mecanismos de mediação do conflito de classe, permeada pela ideologia do Estado Mínimo e pautada nas estratégias de persuasão em detrimento das de coerção (SOUZA, s. d., p. 5).

No âmbito superestrutural, compreendido como unidade orgânica indissociável da estrutura para a solidificação desse processo, frações da burguesia passam a materializar por vias políticas, culturais e ideológicas, no seio da sociedade civil, a ampliação dos mecanismos de consenso/consentimento ativo e passivo (GRAMSCI, 2011) ao projeto do capital. Este rearranjo se assenta inicialmente nos pressupostos políticos originados da Sociedade de Mont Pèlerin ${ }^{10}$, engendrados pela teoria econômica neoclássica, com contribuições teóricas das Escolas Austríaca e

\footnotetext{
6 "O sistema sociometabólico do capital tem seu núcleo formado pelo tripé capital, trabalho assalariado e Estado, três dimensões fundamentais e interrelacionadas" (ANTUNES, 2011, p. 11 - grifos do autor). No capitalismo, estes três elementos instituem a reprodução material e imaterial da totalidade sistêmica do capital, sendo entes indissociáveis para a realização de mais-valor, assim como da própria reprodução das relações sociais de produção.

70 mesmo constitui-se pela reconsideração da importância do Estado Ampliado (GRAMSCI, 2011) no processo socioeconômico, tendo em vista a viabilização, cada vez mais efêmera de acordo com o caráter programático em sua superficialidade, do sistema do capital.

80 conceito gramsciano de bloco histórico se refere à relação dialética entre estrutura e superestrutura, diante da unidade orgânica que tal relação produz para o ordenamento de uma organização social concreta (PORTELLI, 1977, p. 15). 0 conceito se refere a uma situação histórica que confere a uma classe, e as respectivas alianças, a hegemonia no bojo de sua edificação e do projeto classista em si. Assim, entende-se que a abordagem posta pelo conceito se refira estritamente à aliança de classes para lograr coesão a determinado projeto hegemônico e sua natureza. Neste contexto, compreendemos que a classe burguesa "encontra-se em uma situação de dupla proeminência: a nível estrutural, porque é a classe fundamental no campo econômico; a nível superestrutural, porque tem a direção ideológica através do bloco intelectual" (Ibidem, p. 78).

${ }^{9}$ Tais transformações se colocam na agenda programática alternativa do capital para conservar suas bases de acumulação em novo prisma, permeada pela acumulação flexível em escala mundial (HARVEY, 1993), indissociável da mundialização financeira do capital (CHESNAIS, 1996).

${ }^{10}$ Esta seria "uma espécie de franco-maçonaria neoliberal, altamente dedicada e organizada, com reuniões internacionais a cada dois anos. Seu propósito era combater o keynesianismo e o solidarismo reinantes e preparar as bases de um outro tipo de capitalismo, duro e livre das regras para o futuro" (ANDERSON, 1995, p. 10). Sua gênese pode ser demarcada após a publicação da primeira edição do livro 0 caminho da servidão, de Friedrich Hayek, no ano de 1944. Contudo, diante do contexto de ascensão do Estado de Bem-Estar Social europeu, e do New Deal norte-americano, evidencia-se o recuo político das teses neoliberais, que passam, através dos encontros bianuais, a partir de 1947, a estabelecer premissas teóricas contrárias ao intervencionismo estatal na economia.
} 
de Chicago. Sob esta égide, deflagra-se a redefinição do papel do Estado após a progressiva estratégia de supressão do Welfare State ${ }^{11}$, por meio da apologia ao Estado Mínimo, da racionalização dos investimentos sociais, privatização dos serviços estatais e a reconfiguração dos mecanismos de mediação do conflito de classes, principalmente em sua atuação como intermediário na relação capital-trabalho.

Entretanto, diante do desgaste do modelo neoliberal ortodoxo, principalmente durante a década de 1990, ascende o movimento de reestruturação do Estado sob os pressupostos neoliberais mediados pelas premissas da Terceira Via. Tais mutações tem como marca a manutenção da apologia do Estado Mínimo sob o discurso da eficiência da "máquina pública", o protagonismo social, a racionalização dos gastos públicos com políticas sociais, publicização e descentralização executiva das atividades exclusivas do Estado, incentivo às parcerias público-privadas, e a reconfiguração dos mecanismos de mediação do conflito de classes ante à redefinição dos imperativos éticos do capital, projetados agora por uma "face mais humana" (NEVES; MARTINS, 2005; ANTUNES, 1999).

No caso brasileiro, essa etapa pode ser demarcada após o governo Fernando Henrique Cardoso, que dentre as múltiplas ações deste teor para a educação, implementou no bojo das políticas educacionais elementos ético-políticos no âmbito pedagógico-curricular ${ }^{12}$, através da disseminação de imperativos éticos como a sustentabilidade, empreendedorismo, cidadania ativa, etc., para a formação do "trabalhador de novo tipo", assim como na gestão programática, diante da ampliação da participação da sociedade civil na oferta educacional.

\section{As prescrições curriculares e a geografia que se ensina para a EJA: o caso do PROJOVEM Urbano.}

Tais reorientações programáticas originou a reestruturação das políticas públicas para a EJA. Isto pode ser identificado principalmente com a criação Programa Nacional de Inclusão de Jovens: Educação, Qualificação e Ação Comunitária (Projovem) e suas ramificações, o Programa Nacional de Integração da Educação Profissional com Educação Básica na Modalidade Educação de Jovens e Adultos (PROEJA), e o Programa Nacional de Acesso ao Ensino Técnico e Emprego (Pronatec). Tal intento reestruturou em grande parte a EJA no país, devido à integração da escolarização básica ao ensino técnico-profissionalizante, mantendo o foco principal na inserção dos jovens ${ }^{13}$ excluídos do mundo do trabalho. Tal estratagema se enquadra na análise de Neves (2005) acerca da consolidação da nova pedagogia da hegemonia. Isto por sedimentar a educação para o desemprego, principalmente pela repolitização da classe trabalhadora e a apologia da empregabilidade, além de consolidar elementos indissociáveis da nova cultura cívica.

À escola, portanto, é transmitida a tarefa de ensinar as futuras gerações a exercer uma cidadania de "qualidade nova", a partir do qual o espírito de competitividade seja desenvolvido em paralelo ao espírito de solidariedade, por intermédio do abandono da perspectiva de classe e da execução de tarefas de caráter tópico na amenização da miséria em nível local (NEVES, 2005, p. 211 - grifos do autor).

\footnotetext{
11 “Se acrescenta um discurso ideológico auto-incriminatório que iguala tudo o que é estatal com a ineficiência, a corrupção e o desperdício, enquanto que a "iniciativa privada" aparece sublimada como a esfera da eficiência, da probidade e da austeridade” (BORÓN, 1995, p. 78).

12 Destacamos aqui o Exame Nacional para Certificação de Competências de Jovens e Adultos (Encceja), A Lei de Diretrizes e Bases da Educação Nacional (LDB), e o Parecer 11/2000 de 10 de maio de 2000, que resultou nas Diretrizes Curriculares para a EJA.

${ }^{13}$ Ressaltamos que o Programa Nacional de Inclusão de Jovens (Projovem), principalmente após a criação do Projovem Adolescente, limita as inscrições pela faixa etária dentre 15 e 29 anos. Sobre o debate acerca da juvenilização da modalidade de ensino, muito analisada no campo da educação, cabe destacar que a temática vem sendo destacada nos relatórios da Organização para a Cooperação e Desenvolvimento Econômico (OCDE, 2013), assim como a Organização Internacional do Trabalho (OIT, 2013). Ambos destacam relevância dos dados acerca do desemprego juvenil, contabilizado em 15\% deste segmento demográfico, em conjunto com a baixa escolarização do mesmo segmento etário - segundo os dados da 0CDE, aproximadamente 8,5 milhões de jovens brasileiro não concluíram a educação básica. Neste sentido, corroboramos com os estudos de Souza (2011) e Gouveia (2014), onde é discriminado que a juvenilização da modalidade é estratégica diante dos problemas enfrentados por esse segmento etário, e principalmente a sua potencialidade para ocasionar distúrbios à ordem hegemônica.
} 
Sob essas considerações passamos a analisar como os mecanismos curriculares para a EJA, e respectivamente suas diretrizes, consolidam os objetivos político-pedagógicos ante o processo de recomposição burguesa, destacando principalmente dois aspectos: a sobrevalorização de valores para o exercício da "cidadania de qualidade nova", e as competências para o ingresso de jovens excluídos no mercado de trabalho na conjuntura de desemprego estrutural.

A formação/qualificação profissional e social surge neste contexto como demanda objetiva da valorização do capital. De um lado, servindo de instrumento de formação de um exército industrial de reserva de novo tipo - diferente daquele que alimentava a produção fordista. De outro, servindo de espaço de conformação ético-política da classe trabalhadora na nova dinâmica das relações de poder na sociedade, onde os aparelhos privados de hegemonia assumem, na condição de parceiros do Estado, o compromisso de promoção do desenvolvimento social e econômico fundado na ideologia do consenso entre diferentes interesses em conflito (SOUZA, 2012, p. 30).

Uma das faces do programa aqui analisado se assenta em tais pressupostos conjunturais intrínsecos à empregabilidade ${ }^{14}$, tendo como norte as estratégias de geração de renda (BRASIL, 2005). Tal fenômeno é uma marca essencial da reestruturação produtiva, principalmente pela diluição do operário-massa fordista-taylorista, e a ascensão do discurso da inevitabilidade do desemprego e seu ente individualizante que acarreta, segundo Spink (1997, p. 52), o recondicionamento do próprio conceito de cidadania. Isto pode ser conferido em parte no Projeto Pedagógico Integrado do programa em questão, principalmente diante dos objetivos e a estruturação programática, que seria:

\begin{abstract}
Desenvolver um currículo integrado, interdisciplinar e interdimensional, em que o jovem atue como sujeito, construtor de um todo que faça sentido para ele. A idéia é que a aprendizagem só se efetiva realmente quando o aluno consegue relacionar os novos conhecimentos com suas experiências prévias e situá-los em suas diferentes facetas de ser humano. Nessa perspectiva, o currículo do ProJovem Urbano se sustenta na integração de três dimensões fundamentais: a Formação Básica para elevação da escolaridade ao nível da 8aㅗ série do ensino fundamental; a Qualificação Profissional, na forma de qualificação inicial em um arco de ocupações; e a Participação Cidadã que envolve ações comunitárias, culturais, esportivas e de lazer (BRASIL, 2008, p. 16).
\end{abstract}

No entanto, concebida a intencionalidade formativa no atual contexto de crise orgânica do capital, ressaltamos que o programa revela a primazia da participação dos sujeitos em ações comunitárias, entendidas então como o protagonismo na escala local, abarcando atividades culturais, esportivas e em relação ao lazer. Podemos tencionar que tal pressuposto é limitante da condição cidadã, e derivado direto de sua recomposição despolitizadora, vide a fenomênica (im)potencialidade da escala do lugar para a superação dos dilemas existenciais, sem abarcar as contradições sistêmicas do capital que lograram um novo sentido para o indivíduo em si (SANTOS, 2007). Além disso, destacamos no segundo momento que a concepção de currículo integrado definida pelo programa, assim como indissociável da reestruturação da EJA no país atende segundo Santos (2009, p. 4), a uma concepção instrumental e flexível, em paralelo à própria dimensão produtiva, com novos mecanismos e intencionalidades formativas. 0 mesmo tem como pressuposto a imbricação dos conteúdos às situações do cotidiano, apontando para a particularidade de cada ciência ante esta finalidade, partindo do conhecimento prévio, com foco principal na captura da

\footnotetext{
${ }^{14} \mathrm{O}$ conceito de empregabilidade "desloca a responsabilidade do desemprego da estrutura social e econômica para a pessoa que busca trabalho. Seu emprego depende unicamente de suas qualificações, isto é, de seu grau de empregabilidade. Mais do que uma simples noção, empregabilidade é uma forma de transformação da subjetividade, da identidade" (SILVA, 1999, p. 81).
} 
subjetividade juvenil.

Esta característica aqui apontada no processo de reconfiguração do currículo se aloca no processo de reestruturação produtiva, naquilo que Alves (2011) denomina de "captura da subjetividade" do trabalhador contemporâneo. Essa estratégia, muito bem propagada sob a ótica do capital pela empresa toyotista, se refere ao novo método de controle por meio da "ressocialização e aculturação pela conformação da subjetividade do trabalhador à lógica do capital" (ALVES, 2011, p. 77). Intrínseca à nova base técnica calcada na reconfiguração do "modelo das competências profissionais", este se configura no "terreno ideológico a partir do qual se disseminam as noções estruturantes de flexibilidade, transferibilidade, polivalência e empregabilidade que irão determinar o uso, controle, formação e avaliação do desempenho da força de trabalho" (ALVES, 2011, p. 76).

Desse modo ressaltamos que, para além dos aspectos ideológicos para a cimentação do envolvimento cooptado, tendo em vista principalmente a "reconstrução" da subjetividade, sob a abstrata terminologia de inserção social, ou no mundo do trabalho, ocorre a instrumentalização dos conhecimentos, que demanda "que se trabalhe com um conteúdo organizado e sistematizado para que se possa avançar, para que se possa "aprender a aprender" (SALGADO, 2012, p. 28-29). Logo, sob o prisma das competências do Relatório Delors (UNESCO, 2000), que visa principalmente a consolidação do consenso ao projeto do capital (SHIROMA et al., 2007), ocorre a integração do Ensino Fundamental ao arco de ocupações, assim como ao desenvolvimento de ações comunitárias.

Tal estratagema se enquadra na análise de Neves (2005), acerca da consolidação da nova pedagogia da hegemonia. Isto por sedimentar a educação para o desemprego, principalmente pela repolitização da classe trabalhadora e a apologia da empregabilidade, e consolidar elementos indissociáveis da nova cultura cívica ${ }^{15}$.

Essa educação vem sendo propagada por diferentes meios, mas a escola continua sendo o espaço privilegiado para a conformação ético-política do "novo homem", de acordo com os princípios hegemônicos. 0 "novo homem", nessa visão de mundo, deve: sentir-se responsável individualmente pela amenização de uma parte da miséria do planeta e pela preservação do meio ambiente; estar preparado para doar uma parcela do seu tempo livre para atividades voluntárias nessa direção; exigir do Estado em senso estrito transparência e comprometimento com as questões sociais, mas não deve jamais questionar a essência do capitalismo. (NEVES, 2005, p. 211 - grifos do autor).

Para análise do currículo do programa, cabe ressaltar que o mesmo fragmenta-se em seis unidades formativas ${ }^{16}$, e as atividades de integração curricular se sedimentam nas sínteses integradoras, no projeto de orientação profissional, no plano de ação comunitária, e na informática. As áreas do conhecimento da formação básica se destoam do arcabouço disciplinar, seguindo as considerações interdisciplinares, estruturando-se em: Ciências Humanas, Língua Portuguesa, Inglês, Matemática e Ciências da Natureza. A ciência geográfica está alocada no campo de Ciências Humanas, seguindo as derivações dos Parâmetros Curriculares Nacionais (PCN).

Sobre a organização curricular da primeira unidade formativa do programa em questão, sob o tema "Juventude e Cultura", encontramos sua estruturação em 10 capítulos ${ }^{17}$. A ciência geográfica encontra-se entrelaçada, por meio do discurso da interdisciplinaridade, em quase todos os momentos. Porém, o quinto capítulo, intitulado "A Geografia e o seu cotidiano", define de fato a

\footnotetext{
${ }^{15}$ Isso é nítido nas orientações gerais do programa: "no desenvolvimento dessa dimensão curricular, os jovens aprendem a avaliar o alcance de suas ações, as formas de encaminhamento das demandas dos cidadãos/grupos sociais e os meios de resposta possíveis, sendo levados a compreender a importância e a eficácia do trabalho coletivo e solidário e tudo que isso pode representar em termos de aprendizado e desenvolvimento de competências e habilidades, visando à participação social e ao exercício da cidadania" (SALGADO, 2012, p. 41).

${ }^{16}$ Juventude e Cultura; Juventude e Cidade; Juventude e Trabalho; Juventude e Comunicação; Juventude e Tecnologia; e Juventude e Cidadania.

17 Quem Sou eu? Quem Somos nós?; O que é ser jovem para você? E para o grupo?; Juventude ou juventudes?;Por que estudar e aprender História?; A Geografia e o seu cotidiano?; Os jovens como produtores de cultura.; Cultura, culturas?;A cultura e a relação dos seres humanos com a natureza.; Os jovens e o meio ambiente: presente e futuro.; Patrimônio cultural e juventude: o que temos a ver com isto?
} 
leitura disciplinar ante o eixo temático mais amplo, como descrito a seguir:

\begin{abstract}
Vivemos em um mundo cheio de informações. Todos os dias chegam as nossas casas, pelo rádio e televisão, notícias sobre o Iraque, os Estados Unidos, a China, a Venezuela e outros cantos do mundo. Sobre o Brasil também há notícias em tempo real: enchentes, mortes no transito, violência nas cidades, acordos e oposições na política, dados sobre a economia, manifestações culturais de diferentes lugares... Como se orientar nesse mundo cheio de informaç̧ões? Como entender o que essas informações realmente significam? Os conhecimentos geográficos são fundamentais para os cidadãos. Esses conhecimentos não só nos permitem compreender as informações que circulam na sociedade sobre o Brasil e o mundo, mas também são importantes para que possamos formular opiniões, pensar coisas novas. Hoje é fundamental ser crítico, compreender e não apenas repetir e aceitar todas as ideias e informações que chegam até nós (SALGADO; AMARAL, 2012, p. 35).
\end{abstract}

Inicialmente destacamos o imperativo geográfico nesta tentativa de sintetizar o papel da geografia no cotidiano, atrelado especialmente à leitura e análise das informações veiculadas na imprensa. Mesmo que seja louvável esta função, tal premissa recai na própria condição já criticada por Lacoste (2005), diante dos dilemas da Geografia dos Professores e a própria Geografia do espetáculo. Segundo o autor, além de tal condição apresentar uma leitura do mundo mais dinâmica e atrativa, confrontando o enfadonho método descritivo-mnemônico, aponta para os sentidos limitantes da própria função da Geografia em se posicionar como um saber estratégico intrínseco, não circunscrito apenas à intencionalidade das representações espaciais, colocando em evidência principalmente sua potencialidade política. Ou seja, será apenas para isso que a mesma serve?

E, por mais que se discrimine a necessária análise e criticidade às informações tomadas como metanarrativas, não é visto no manual didático, assim como nas prescrições curriculares, meios e mecanismos para tal. Ou seja, a problemática em questão está na exposição dos problemas e sua incorporação no papel da geografia, mas sem de fato apresentar os métodos para tal, o que apresenta uma esquiva neste sentido, ou pretextos para a responsabilização docente. Logo, estamos diante de uma ciência que se materializa enquanto indicativos conteudísticos, sem operar minimamente o método para a análise do real, como visto posteriormente no Manual do Aluno.

E para conhecer melhor o mundo em que vivemos que estudamos Geografia. Nesse estudo, a observação, a descrição, a analise são importantes. Sabe por que? A Geografia estuda os modos como os homens constroem e produzem os diferentes lugares, aqueles que estão bem perto de nós e também aqueles que estão distantes (SALGADO; AMARAL, 2012, p. 35).

No segundo momento se observa o distanciamento das informações veiculadas para a análise empírica, mantendo em sua prerrogativa nenhuma distinção metodológica.

Na realidade, esse mundo que esta tão próximo de nós, que vemos diariamente na TV, no supermercado, nas bancas dos camelos, nos outdoors das ruas ainda e difícil de ser compreendido pelo cidadão comum. E aí que reside a importância de estudar Geografia. Através desse estudo, os jovens podem questionar, refletir e compreender melhor o mundo em que vivemos (SALGADO; AMARAL, 2012, p. 37).

Portanto, o que se observa é a continuidade da exposição de indicativos científicos, pautado principalmente pela abundância de conteúdos limitados ao caráter informativo. Ao mesmo tempo, sua reprodução ao longo do manual didático expressa o indivíduo como início, meio e fim, obedecendo as premissas da construção da subjetividade enquanto primazia para a produção do 
sentido da disciplina, sob a concepção de um homem abstrato. Ao mesmo tempo, sob o foco na aprendizagem, desloca o papel intelectual e profissional docente. Isto nos leva a convergir à análise de Santos (2009, p. 15) acerca do mesmo programa.

Aproximação problemática com a abordagem fenomenológica, assim, se torna evidente, confirmada também por uma geografia do comportamento que poucas vezes leva em conta o lugar social, a condição de classe do indivíduo. Além disso, é bem clara na proposta curricular a ausência de conflitos na cidade, no mundo do trabalho e na construção da cidadania. Nesse sentido, ao associar-se ao pensamento único que preconiza o fim dos conflitos e da luta de classes na tentativa de se impor uma mudança cultural a favor da lógica do mercado e da competitividade (SANTOS, 2009, p. 15).

\section{Considerações Finais}

Considerando as premissas indicadas tanto na contextualização sócio-histórica, quanto em relação à reestruturação da EJA no país, o ensino de Geografia, agora no corpo das Ciências Humanas, de acordo com a breve análise exposta, espelha as intenções da Pedagogia da Hegemonia. Isto devido a reprodução da geografia oficial (ROCHA, 2010) nos anseios da construção do consenso para a formação do "trabalhador de novo tipo", sobrelevando valores indissociáveis da reconfiguração dos mecanismos de mediação do conflito de classes, vide a importância da subjetividade na relação ensino-aprendizagem, assim como a cidadania restrita à escala local, concebendo a cultura como ente supra-orgânico. Neste sentido, a Geografia que se quer que se ensine para a classe trabalhadora matriculada no programa discriminado absorve elementos assimétricos da realidade concreta, sob o princípio da totalidade, que determina sua reprodução social e material.

Além disso, as categorias apresentadas para a exposição dos fenômenos sociais não apontam potencialidades para o desvelo das contradições no escopo da espacialidade diferencial (LACOSTE, 1993), sendo elas, sob tal ótica, a-tópicas e a-históricas, principalmente no que tange ao método implícito calcado e delimitado no vivido sem qualquer referência à totalidade concreta. Para o pensamento marxista este método isolaria determinadas categorias pertinentes para a análise da realidade em sua essência contraditória, como por exemplo o exame do valor de troca sem a consideração da população e sua composição em classes, ou o "capital sem trabalho assalariado, sem valor, dinheiro, preços, etc." (MARX, 2007, p. 256), assim como sua historicidade. Por conseguinte, Marx (2007) considera que cientificamente, para a mediação dos fenômenos e sua realidade material e imaterial, as categorias são de vital importância para a análise da realidade, sendo elas tomadas como simples ou complexas, portadoras de abstração fundada no processo histórico real e sua complexificação ao longo do tempo ${ }^{18}$.

Para a consciência - e a consciência filosófica é determinada de tal modo que para ela o pensamento que concebe o homem é o homem real, e o mundo concebido é, como tal, o único mundo real -, pois, o movimento das categorias aparece como o verdadeiro ato de produção - que apenas recebe um impulso do exterior - cujo resultado é o mundo, e isso é exato porque a totalidade concreta, como totalidade do pensamento, como uma concreção do pensamento, é, na realidade, um produto do pensar, do conceber; não é de nenhum modo o produto do conceito que se engendra a si mesmo e que concebe separadamente e acima da intuição e da representação, mas é a elaboração da intuição e da representação em conceitos. 0 todo, tal como aparece no cérebro, como um todo

\footnotetext{
18 Para chegar a essa afirmação, Marx (2007) tomou o trabalho como exemplo, assim como o sistema monetário ao longo da história. Sobre a primeira categoria, Marx afirma que é impossível abstrair de modo mais geral sobre o inexistente, somente ao que é comum à existência humana e, por conseguinte, produto das relações sociais históricas. Ao mesmo tempo, todas as épocas são determinadas por essas abstrações "do mesmo modo o produto de condições históricas não possuem plena validez senão para essas condições e dentro dos limites dessas mesmas condições” (MARX, 2007, p. 262).
} 
mental, é um produto do cérebro pensante, que se apropria do mundo da única maneira em que o pode fazer, maneira que difere do modo artístico, religioso e prático de se apropriar dele. $\mathrm{O}$ objeto concreto permanece em pé antes e depois, em sua independência e fora do cérebro ao mesmo tempo, isto é, o cérebro não se comporta senão especulativamente, teoricamente (MARX, 2007, pp. 257-258).

Portanto, a presente crítica ao método, assim como as finalidades formativas que endossam as prescrições curriculares, adentram nos sentidos expostos e intencionais para a produção do conhecimento e, consecutivamente, a práxis socioespacial. Neste sentido, a apropriação de categorias simples e complexas para o desvelo do real contraditório é um ente estratégico para a existência dos sujeitos em tempos de intensificação da precariedade da vida, do esgotamento do controle sociometabólico, e sua reificação como barbárie (ALVES, 2011), assim como a necessária extrapolação e superação do conceber para o pensar.

Ao individualizar a concepção de cidadania e formação, despreza a própria identificação histórica da modalidade de ensino voltado para a classe trabalhadora, gerando programaticamente a ocultação de instrumentos para a reflexão de sua condição de classe. Para tal, os conteúdos geográficos são desenvolvidos de maneira assertiva, sem apresentar o método científico para o raciocínio espacial e suas contradições na totalidade sistêmica, o que, em nossa interpretação, gera limitantes para a intervenção crítica no espaço geográfico. Portanto, por meio da individualização, reprodução mimética dos conteúdos calcados em significantes abstratos, e a reprodução da responsabilização na escala do lugar, induz aos hiatos estruturantes para a reprodução social e material da vida e ao estranhamento/alienação no sentido marxista do conceito, logrando fôlego ao projeto hegemônico.

\section{Referências}

ALVES, Giovanni. Trabalho e subjetividade: o espírito do toyotismo na era do capitalismo manipulatório. São Paulo: Boitempo, 2011.

ANDERSON, Perry. Balanço do neoliberalismo. In: SADER, E.; GENTILI, P. Pós-neoliberalismo: as políticas sociais e o Estado. Rio de Janeiro: Paz e Terra, 1995.

ANTUNES, Ricardo. "Terceira Via": Uma Via de Continuidade do Neoliberalismo. Debate Sindical, n. 32, 1999.

. Adeus ao trabalho?: ensaios sobre as metamorfoses e a centralidade do mundo do trabalho. 15 ed. São Paulo: Cortez, 2011.

BRASIL. Presidência da República; Coordenação Geral do PROJOVEM. Programa Nacional de Inclusão de Jovens: Educação, Qualificação e Ação Comunitária. Brasília: Presidência da República, 2005. Disponível em: <http://www.projovem.gov.br/docs/ppi.pdf>. Acesso em: 20 de maio de 2017.

Presidência da República; Secretaria-Geral da Presidência da República; Secretaria Nacional de Juventude; ProJovem Urbano. Projeto Pedagógico Integrado do ProJovem Urbano. Brasília: Presidência da República, 2008.

CHESNAIS, François. A mundialização do capital. São Paulo: Xamã, 1996.

FRIGOTT0, Gaudêncio. A produtividade da escola improdutiva: um (re)exame das relações entre educação e estrutura econômico-social capitalista. 9 ed. São Paulo: Cortez, 2010.

GOUVEIA, Fernanda Paixão de Souza. Juventude, Políticas de Formação e Qualificação Profissional. In: GOUVEIA, F. P. de S.; SILVA, T. M. A. da (Orgs.). Contribuições para o debate sobre a Educação de Jovens e Adultos. Curitiba: Appris, 2014.

GRAMSCI, Antonio. Cadernos do cárcere. Volume 3 - Maquiavel: notas sobre o estado e a política. Rio 
de Janeiro: Civilização Brasileira, 2011.

HADDAD, Sérgio; DI PIERRO, Maria Clara. Diretrizes da Política Nacional de Educação de Jovens e Adultos - Consolidação de documentos 1985/1994 São Paulo, 1994. (mimeo.).

HARVEY, David. A Condição Pós-moderna. 2. ed. São Paulo: Loyola, 1993.

INEP. Censo Escolar da Educação Básica. Brasília, DF: INEP, 2016.

LACOSTE, Yves. A geografia-isso serve, em primeiro lugar, para fazer a guerra. São Paulo: Papirus, 2005.

MARX, Karl. Contribuição à crítica da economia política. São Paulo: Expressão Popular, 2007.

MÉSZÁROS, István. Crise estrutural do capital. São Paulo: Boitempo, 2011.

. Para além do capital. São Paulo: Boitempo, 2011a.

NEVES, Lúcia Maria Wanderley (Org.). A nova pedagogia da hegemonia: estratégias do capital para educar o consenso. São Paulo: Xamã, 2005.

POULANTZAS, Nico. As classes sociais no capitalismo de hoje. Rio de Janeiro: Editora Zahar, 1978.

RIBEIRO; Ricardo de Souza. SOUZA, José dos Santos. Políticas públicas para a formação profissional e conformação social de jovens: algumas referências preliminares sobre o ProJovem. In: SOUZA, J. dos S (Org.). Reflexões da prática docente na EJA. Seropédica: EDUR, 2010.

ROCHA, Genylton Odilon Rêgo da. O Ensino de Geografia no Brasil: as prescrições oficiais em tempos neoliberais. Revista Contrapontos, v. 10, n. 1, p. 14-18, 2010.

SALGADO, Maria Umbelina Calafa (Org.). Manual do Educador: orientações gerais. Brasília: Programa Nacional de Inclusão de Jovens - Projovem Urbano, 2012.

; AMARAL, Ana Lúcia (Orgs.). Guia da Estudo: Unidade formativa I. Brasília: Programa Nacional de Inclusão de Jovens - Projovem Urbano, 2012.

SANTOS, Enio Serra dos. A cidade como eixo estruturante da geografia a ser ensinada no projovem urbano. Anais do $10^{\circ}$ Encontro Nacional de Prática de Ensino em Geografia. Porto Alegre; Rio Grande do Sul, 2009.

Geografia do trabalho e escolarização de jovens e adultos: notas sobre a educação geográfica do trabalhador. Anais da XIII Jornada do Trabalho. Presidente Prudente; São Paulo, 2012.

SANTOS, Milton. Espaço do Cidadão. São Paulo: Edusp, 2007.

SHIROMA, Eneida Oto; MORAES, Maria Célia Marcondes de; EVANGELISTA, Olinda. Política Educacional. Rio de Janeiro: Lamparina, 2007.

SILVA, Tomaz Tadeu da. Educação, trabalho e currículo na era do pós-trabalho e da pós-política. In: FERRETI, C. J.; SILVA JÚNIOR, J. dos R. (orgs.). Trabalho, formação e currículo: para onde vai a escola? São Paulo: Xamã, 1999.

SOUZA, José dos Santos. A reconfiguração do trabalho, da produção e dos mecanismos de mediação do conflito de classe e a formação do trabalhador. S.d. Disponível em: <https://www.ifch.unicamp.br/formulario_cemarx/selecao/2012/trabalhos/7144Souza_Jose.pdf>. Acesso em: seis de maio de 2017.

A EJA no contexto das políticas públicas de inclusão de jovens no mercado de trabalho. In:

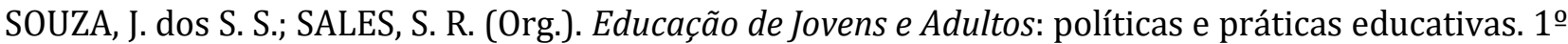
ed. Rio de Janeiro: Nau Editora; EDUR, 2011.

SPINK, Peter. Empregabilidade. In: CASALI, A. et al. Empregabilidade e educação: novos caminhos no mundo do trabalho. São Paulo: EDUC, 1997.

UNESCO. Educação: um tesouro a descobrir. São Paulo: Cortez; Brasília, DF: MEC: UNESCO, 2000. 